\title{
Aprendizagem ao longo da vida: a universidade da maturidade e o aprender a ser velho
}

\author{
Lifelong learning: the maturity university and learning to be old
}

Aprendizaje permanente: la universidad de madurez y aprendizaje a ser viejo

\author{
Kely Rejane Souza dos Anjos de Carvalho \\ Instituto Federal de Tocantins - IFTO - Tocantins - Brasil \\ ORCID: https://orcid.org/0000-0001-6683-839X \\ Endereço currículo Plataforma Lattes: http://lattes.cnpq.br/5678865861173429 \\ E-mail: kelyrejanecarvalho@gmail.com \\ Pabla Cassiãngela Silva Milhomem \\ Universidade Federal de Tocantins - UFT - Tocantins - Brasil \\ ORCID: https://orcid.org/0000-0003-4473-3313 \\ Endereço currículo Plataforma Lattes: http://lattes.cnpq.br/2664514278077115 \\ E-mail: pabla.milhomem@ifto.edu.br \\ Isabella Cristina Aquino Carvalho \\ Universidade Federal de Tocantins - UFT - Tocantins - Brasil \\ ORCID: https://orcid.org/0000-0002-9818-9934 \\ Endereço currículo Plataforma Lattes: http://lattes.cnpq.br/0026854025942795 \\ E-mail: isabellacrisaquinocar@gmail.com \\ Ricardo Furtado de Oliveira \\ Universidade Federal de Tocantins - UFT - Tocantins - Brasil \\ ORCID: https://orcid.org/0000-0001-5374-0385 \\ Endereço currículo Plataforma Lattes: http://lattes.cnpq.br/5832830245348799 \\ E-mail: ricardopsicologo@ live.com \\ Maiara Sobral Silva \\ Instituto Federal de Tocantins - IFTO - Tocantins - Brasil \\ ORCID: https://orcid.org/0000-0001-9558-4333 \\ Endereço currículo Plataforma Lattes: http://lattes.cnpq.br/2804075168986956 \\ E-mail: maiara@ifto.edu.br
}

Resumo: O vertiginoso aumento da informação e o acelerado avanço tecnológico impõem à educação e aos seus protagonistas novos paradigmas e novas demandas para o ensino e para a aprendizagem. Nessa conjuntura, a Universidade da Maturidade (UMA), vinculada à Universidade Federal do Tocantins (UFT), surge como proposta para desenvolver, no campo educacional, uma aprendizagem ao longo da vida, de maneira a possibilitar aos alunos a troca de experiências por meio das relações intergeracionais. O objetivo deste artigo é discutir a UMA como um espaço educacional de aprendizagem ao longo da vida do indivíduo. Para o estudo, optamos pela metodologia da história oral temática. A partir da análise das entrevistas, concluímos que a UMA é um processo integrador, que dá condições aos estudantes idosos de ressignificar sua vivência e ainda contribuir ativamente na sociedade. 


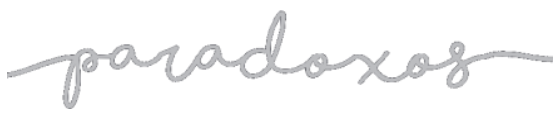

Aprendizagem ao longo da vida: a universidade da maturidade e o aprender a ser velho

Palavras-chave: Aprendizagem ao longo da vida. UMA/UFT. Educação. Educação intergeracional.

Abstract: The vertiginous increase in information and the accelerated technological advance impose on education and its protagonists new paradigms and new demands for teaching and learning. In this context, the University of Maturity (UMA), linked to the Federal University of Tocantins (UFT), emerges as a proposal to develop, in the educational field, lifelong learning, in order to enable students to exchange experiences through intergenerational relations. The purpose of this article is to discuss UMA as an educational space for lifelong learning for the individual. For the study, we chose the thematic oral history methodology. From the analysis of the interviews, we conclude that UMA is an integrating process, which allows elderly students to reframe their experience and still actively contribute to society.

Keywords: Lifelong learning. UMA / UFT. Education. Intergenerational education.

Resumen: El aumento vertiginoso de la información y el avance tecnológico acelerado imponen a la educación y a sus protagonistas nuevos paradigmas y nuevas demandas de enseñanza y aprendizaje. En este contexto, la Universidad de la Madurez (UMA), vinculada a la Universidad Federal de Tocantins (UFT), surge como una propuesta para desarrollar, en el campo educativo, el aprendizaje permanente, a fin de permitir a los estudiantes intercambiar experiencias a través de relaciones intergeneracionales El propósito de este artículo es discutir la UMA como un espacio educativo para el aprendizaje permanente para el individuo. Para el estudio, elegimos la metodología temática de historia oral. Del análisis de las entrevistas, llegamos a la conclusión de que UMA es un proceso integrador, que permite a los estudiantes mayores reformular su experiencia y aún contribuir activamente a la sociedad.

Palabras clave: Aprendizaje permanente. UMA / UFT. Educación. Educación intergeneracional.

\section{INTRODUÇÃO}

A educação passa por uma crise de valores e identidade e consequentemente de finalidade. Portanto, faz-se necessária a ampliação da aprendizagem humana não apenas sob a ótica biológica, mas em vertentes antropológicas, sociológicas e 


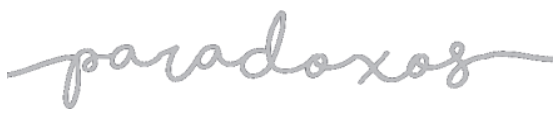

Aprendizagem ao longo da vida: a universidade da maturidade e o aprender a ser velho

CARVALHO, MILHOMEM, CARVALHO, OLIVEIRA, SILVA, 2020

existenciais, pensando os sujeitos em sua complexidade, no encontro des ses diversos campos do conhecimento. Considerando que o ofício da educação está diretamente ligado à condição humana, que por sua vez está intrinsecamente ligada ao tempo, compreende-se a necessidade de não só nascer, mas também de aprender para desenvolver-se. Nessa perspectiva, a educação não pode ser entendida apenas como instrução, mas como promoção de modelos que possibilitem desenvolver capacidades sociocognitivas do sujeito educando.

O ser humano, diferentemente dos outros animais, passa por um processo cultural que o torna "humano", capaz de aprender a aprender, tornando-se um ser cultural com habilidades de criar, inventar e reinventar. Nesse panorama, entende-se que os indivíduos em todas as fases da vida têm a necessidade e a possibilidade de aprendizagem através de interações, o que os humaniza e qualifica o processo de desenvolvimento humano. Compreende-se, pois, que quanto mais buscamos aprender mais nos tornamos essencialmente humanos.

Os outros seres vivos já nascem sendo o que definitivamente são, o que hão de ser irremediavelmente aconteça o que acontecer, ao passo que de nós humanos, o que parece mais pudente dizer é que nascemos para a humanidade [...] (SACRISTÁN, 2000, p. 24).

Nessa conjuntura, a UMA surge como o local de interações e busca de uma velhice bem-sucedida e saudável, a partir das vivências e dos desafios de se trabalhar com a terceira idade democratizando seu acesso a bens comuns, tornando-se assim, um objeto de reflexão para toda a sociedade no campo da gerontologia.

A fim de compreender, por meio da história oral temática, como o projeto UMA pode ser um campo educacional de aprendizagem ao longo da vida, apresentamos, inicialmente, os preceitos legais que amparam a pessoa idosa sob a luz das políticas públicas voltadas para esse público. Em seguida, focaremos na contextualização histórico-social da UMA, estabelecida na Universidade Federal do Tocantins, com polos nas cidades de Palmas, Araguaína, Brejinho do Nazaré, Miracema, Porto Nacional, Arraias, Gurupi, Tocantinópolis, e em Campina Grande (PA), além da Universidade Federal do Paraná e da Universidade do Amapá.

Por conseguinte, abordaremos o envelhecimento como modo de vida saudável, ativo e confiante. 


\section{PROCEDIMENTOS METODOLÓGICOS}

A abordagem deste trabalho é qualitativa, com natureza descritiva e procedimentos metodológicos baseados no método de pesquisa da história oral, que é esclarecido por Thompson (2002, p. 9) como "a interpretação da história e das mutáveis sociedades e culturas através da escuta das pessoas e do registro de suas lembranças e experiências".

Após concluído o levantamento documental e bibliográfico da literatura sobre o tema, nos apoiamos na história oral temática, por compreendermos que esse método de pesquisa se compromete a esclarecer o tema estudado a partir de um ponto de vista, a fim de atender o objetivo pretendido. Para Alberti (2005, p. 37), “as entrevistas temáticas são aquelas que versam prioritariamente sobre a participação do entrevistado no tema escolhido". A aprendizagem ao longo da vida fomentada pela percepção de três alunas quanto ao papel da UMA no aprender ser velho constituem o eixo temático deste estudo bem como o norteamento das entrevistas realizadas.

A entrevista é definida como "um encontro entre duas pessoas, a fim de que uma delas obtenha informações a respeito de determinado assunto, mediante uma conversação de natureza profissional” (MARCONI; LAKATOS, 2003, p. 195). Neste estudo, utilizamos tal recurso como instrumento de coletar dados. Sendo que as análises das narrativas, amparadas pela história oral, buscaram diagnosticar e tratar o problema aqui proposto. Dessa forma, as narrativas colhidas junto às alunas da UMA, por intermédio de um roteiro semiestruturado de perguntas e um gravador digital, além de fornecer esclarecimentos quanto à oferta da educação para velhos, também enriqueceu consideravelmente nosso trabalho.

\section{POLÍticas públicas PARA A PESSOA IDOSA: MARCOS LEGAIS E REGULATÓRIOS}

É de fundamental importância admitir que o envelhecimento não é igual para todos. As diferenças existentes dizem respeito a diversos fatores que podem ser o diferencial no modo de vida da pessoa idosa. Indicadores como acesso aos bens e 
serviços, cobertura da rede de proteção, condições de atendimento social, convivência social e familiar, entre outros, são fomentadores de uma velhice saudável e feliz.

Dentro dessa ótica, dados da Pesquisa Nacional por Amostra de Domicílios Contínua (PNAD), realizada pelo Instituto Brasileiro de Geografia e Estatística (IBGE, 2016), entre 2012 e 2016, revelam que a população idosa (com 60 anos ou mais de idade) cresceu 16,0\%, tendo chegado a 29,6 milhões de pessoas, o equivalente a 14,4\% da população brasileira, que atualmente é de 205,5 milhões de pessoas (IBGE, 2016). Dados confirmam o significativo aumento do número de idosos e faz uma projeção: “em 1950, o Brasil tinha 2 milhões de pessoas com mais de 60 anos. Em 1965 esse número saltou para 6,2 milhões. Na virada do século chegou a 13,9 milhões e, em 2025, chegará a 31,8 milhões ${ }^{1}$ ”.

Desse modo, há que se pensar na qualidade de vida dessa faixa etária da população, que está cada vez mais representativa e por isso merece mais atenção tanto da sociedade quanto do poder público, em especial. A velhice é um momento da vida em que políticas públicas regulatórias de amparo e assistência social podem ser um diferencial. No que diz respeito aos marcos legais relacionados aos direitos dos idosos, o primeiro marco surgiu em 1948, quando a Assembleia Geral das Nações Unidas adotou e proclamou a Declaração Universal dos Direitos Humanos (DUDH), em seu artigo 25:

Toda pessoa tem direito a um padrão de vida capaz de assegurar a si e a sua família saúde e bem-estar, inclusive alimentação, vestuário, habitação, cuidados médicos e os serviços sociais indispensáveis, e direito à segurança, em caso de desemprego, doença, invalidez, viuvez, velhice ou outros casos de perda dos meios de subsistência em circunstâncias fora de seu controle (DUDH, 1948, p.13).

Um segundo marco está na Constituição Brasileira de 1988, que foi fundamental para a consolidação dos direitos constitucionais da pessoa idosa, visto que declara todos os direitos dos cidadãos, sem distinção de raça, sexo, cor, língua, religião, política, riqueza ou de qualquer outra natureza. Entre os vários artigos que defendem os direitos dos idosos, vejamos o que um deles afirma:

Artigo 203 - A assistência social será prestada a quem dela precisar, independentemente de contribuição à seguridade social, e tem por objetivos: I - a proteção à família, à maternidade, à infância, à adolescência e à velhice.

\footnotetext{
${ }^{1}$ Luiz Roberto Ramos, professor da Escola Paulista de Medicina (UPM) da Universidade Federal de São Paulo (Unifesp), em fala realizada durante a $68^{a}$ Reunião da Sociedade Brasileira para o Progresso da Ciência (SBPC) em julho de 2016.
}

DOI: http://doi.org/10.14393/par-v5n1-2020-54300 - Paradoxos, Uberlândia, v. 5, n. 1, p. 101-116, jan./jun. 2020 |105 


\begin{abstract}
V - a garantia de um salário mínimo de benefício mensal à pessoa portadora de deficiência e ao idoso que comprovem não possuir meios de prover à própria manutenção, ou de tê-la provida por sua família, conforme dispuser a lei (CF, 1988).
\end{abstract}

No entanto, a consolidação dessa política assistencialista aconteceu somente em 1993, com a promulgação da Lei Orgânica da Assistência Social (LOAS), que "[...] instituiu uma política de mínimos sociais e de atendimento de necessidades básicas para grupos vulneráveis: crianças, jovens, idosos deficientes e famílias pobres" (BILAC, 2014, p. 91).

No que se refere à assistência social, o Ministério do Desenvolvimento Social e Combate à Fome (MDS), por intermédio da Secretaria Nacional de Assistência Social (SNAS) e do Conselho Nacional de Assistência Social (CNAS), instituiu no Brasil, em 2004, a Política Nacional de Assistência Social (PNAS), que “[...] garante à pessoa idosa e a sua família o acesso a programas, serviços, projetos e benefícios que contribuam para a efetivação de seus direitos" (GOMES, 2009, p. 19).

No ano seguinte, foi criado o Sistema Único de Assistência Social (SUAS), que é um modelo único de gestão da Política de Assistência Social em âmbitos federal, estadual e municipal e que regulamentou o seguinte:

\footnotetext{
A atual concepção da assistência social como política pública de direitos voltada à prevenção, proteção, inserção e promoção social, desenvolvida em conjunto com outras políticas públicas, reverte o paradigma de caráter clientelista, imediatista e assistencialista que sempre marcou essa área. (GOMES, 2009, p. 14).
}

Após a promulgação da Constituição de 1988, outras leis surgiram no intuito de amparar a pessoa idosa, entre elas: o Código de Defesa do Consumidor (1990), o Estatuto do Ministério Público da União (1993), a Lei Orgânica da Assistência Social (Loas, 1993), a Política Nacional do Idoso (1994), o Estatuto do Idoso (2003) e a Política Nacional de Saúde da Pessoa Idosa (2006). No âmbito do estado do Tocantins, foram aprovados: a Lei n. ${ }^{\circ} 2.001$, em 2008, que dispõe sobre a concessão da gratuidade dos transportes rodoviário e aquaviário intermunicipal a passageiros com idade acima de 60 anos; o Conselho Estadual do Idoso (2002); a Lei Municipal n. ${ }^{\circ}$ 1.888, de 2012, que dispõe sobre a Política Municipal de Atendimento e Amparo ao Idoso, no município de Palmas - TO.

No que diz respeito à relação do idoso com a educação, mais especificamente com o ensino superior, vejamos o que diz o artigo 25, previsto no Estatuto do Idoso: 
O poder público apoiará a criação de universidade aberta para as pessoas idosas e incentivará a publicação de livros e periódicos, de conteúdo e padrão editorial adequados ao idoso, que facilitem a leitura, considerada a natural redução da capacidade visual (BRASIL, 2003, n. p.).

Dentro dessa lógica, Melo (2010, p. 23) esclarece:

As Universidades da Terceira Idade têm representado uma experiência significativa, visto que proporcionam aos idosos a oportunidade de se manterem atualizados, além de realizarem contatos com pessoas motivadas a prosseguir na busca de novos conhecimentos.

Após apresentadas as referências legais, focaremos a UMA como política pública voltada para o bem-estar social, emocional e elevação da autoestima por meio do aumento da escolarização.

\section{ENVELHECIMENTO E APRENDIZAGEM AO LONGO DA VIDA}

Minayo e Coimbra (2002, p. 14) apontam o envelhecimento como uma categoria a ser analisada de forma diferente por cada país, tendo como referência especialmente a expectativa de vida instaurada naquele locus. Em seu estudo, afirmam que, mais do que um processo biológico assegurado pela evolução orgânica, envelhecer se traduz em uma formação social e cultural historicamente construída e instaurada pelas possibilidades sociais estabelecidas e que decretam funções para cada grupo composto por determinada faixa etária.

Desse modo, é preciso entender o idoso sob dois aspectos: primeiramente, sob o aspecto do próprio ciclo etário, estabelecido no Brasil pela idade de 60 anos, conjuntamente com outros países que participaram da 1. a Assembleia Mundial sobre o Envelhecimento, realizada em 1982 pela Organização das Nações Unidas (ONU). Em segundo lugar, os aspectos sociais instaurados aqui logram configurações relativas a questões como saúde e produtividade econômica e apresentam elementos a serem analisados, porquanto implicam na constituição da vivência do velho e, consequentemente, no envelhecimento.

Para Teixeira (2008), no final da década de 1960, houve um aumento considerável da população chamada de terceira idade. Atualmente esse público 


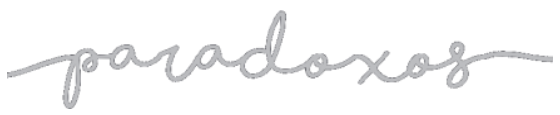

Aprendizagem ao longo da vida: a universidade da maturidade e o aprender a ser velho

ultrapassa os 26 milhões (TEIXEIRA, 2008). Moragas (1997) realça que existem três tipos de concepções e conceituações da velhice elencadas em inúmeros aspectos.

A primeira concepção, definida como velhice cronológica, inicia-se aos 65 anos, com base no período em que a pessoa se afasta de suas atividades laborais. Fundamentase na velhice histórica real, ou seja, é medida pelo transcurso do tempo agrupado em anos, décadas, o que determina os grupos etários a que a população pertence.

A crítica que o autor faz a essa concepção diz respeito à não análise do contexto sociocultural a que pertence o velho ou a pessoa idosa, pois uma mesma idade apresenta diferentes características nos aspectos relativos à saúde física e mental, à educação, entre outros determinantes.

A segunda concepção, a de velhice funcional, para o autor, é um conceito errôneo, pois caracteriza a velhice como o estágio da vida em que o ser humano se encontra incapacitado ou mesmo funcionalmente limitado. De acordo com Moragas (1997), a população idosa vem gradativamente perdendo sua capacidade psicomotora. O autor enfatiza ainda que é natural do humano, ao envelhecer, ir reduzindo sua capacidade funcional devido ao transcurso do tempo, contudo a velhice possui sua própria funcionalidade e suas limitações. Nesse aspecto, entende-se que a velhice não impede que o indivíduo tenha uma vida saudável e ativa.

Finalmente, a concepção de velhice como etapa vital é a que mais se adequa à contemporaneidade do velho, tendo equilíbrio entre as condições de vida e da sociedade a que pertence, bem como sua idade cronológica e o transcurso ao qual vivenciou. Tal concepção não nega as limitações decorrentes do processo de envelhecer, contudo leva em conta as potencialidades desenvolvidas ao longo da vida - maturidade, experiências, paciência -, baseando-se no reconhecimento de que cada etapa da vida possui suas peculiaridades, limitações e individualidades, que durante o transcorrer do tempo produz efeitos. Assim, a velhice como etapa vital vem de encontro às práticas da psicologia do desenvolvimento humano. "A velhice constitui uma etapa a mais da experiência humana, conhecido o mínimo de aptidão funcional e status socioeconômico e, portanto, pode e deve ser uma fase positiva do desenvolvimento individual e social" (MORAGAS, 1997, p. 20).

Para melhor discussão, é importante compreendermos como as concepções de velho e de velhice são construídas histórica e socialmente no Brasil. Ao apresentar os significados e as conceituações sociais da velhice, cumpre destacar que, ao longo da história da DOI: http://doi.org/10.14393/par-v5n1-2020-54300 - Paradoxos, Uberlândia, v. 5, n. 1, p. 101-116, jan./jun. 2020 |108 


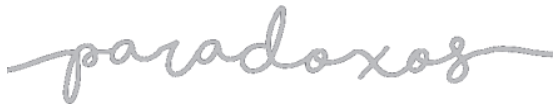

Aprendizagem ao longo da vida: a universidade da maturidade e o aprender a ser velho

CARVALHO, MILHOMEM, CARVALHO, OLIVEIRA, SILVA, 2020

humanidade, os aspectos, os signos ligados à velhice desde os tempos da Babilônia até os dias atuais passaram e passam por diversos significados para as sociedades, desde sábio e ancião a um fardo inútil e obsoleto sem prestígio social algum (OTSUKA, 2010). Percepção que é complementada por Paula (2015, p. 22) ao argumentar que

Comumente se considera o envelhecer às pessoas de idade mais avançada. Todavia, o envelhecimento é um processo inerente ao ser humano, que acontece diariamente desde o nascimento e só termina com a morte. Pode-se afirmar que é o único termo passível de conceituação universal, apesar de possuir formas e características variáveis a cada pessoa a que ele se submete.

Diante do exposto acerca do envelhecimento, visando a compreensão do velho como aprendiz ao longo da vida, é fundamental que esclareçamos a conceituação sobre aprender durante toda a vida. Cabe ressaltar que estamos em constante processo de aprendizagem durante todas as fases, nos mais diversos ambientes (formais e não formais), para conhecer, apreender, bem como compreender determinado assunto, teoria, atividade em geral, através do desenvolvimento de competências e habilidades desenvolvidas ao longo de nossa existência conforme disserta Portilho (2008, p. 23):

Todos podem ser aprendizes especialistas, independentemente do tempo, espaço e habilidade. Sempre é hora de aprender! E isso não significa que todos vão se dar bem em todas as áreas e situações. Temos nossas diferenças, facilidades e preferências. É importante saber que aprender ao longo da vida incluiu a abertura a novas possibilidades, novos caminhos e novas tentativas. É darmos conta de nós mesmos, como alguém que ao aprender se percebe, se constrói, se transforma.

Nesse cenário, a aprendizagem não deve estar restrita ou ser pensada como um aprender que ocorre somente em ambientes de educação formal, com currículos definidos. Deve-se reconhecer que todos os lugares são propícios ao conhecimento e que estamos em constante formação, num processo flexível ao tempo, ao espaço, às técnicas, assim como ao contexto sociocultural em que nos inserimos.

\section{A GERONTOLOGIA SOCIAL}

Com a iminente transição demográfica, os avanços da medicina, as melhorias das práticas de prevenção à saúde, as novas perspectivas de longevidade e novas pesquisas, surgiu também a necessidade de repensar a velhice a partir de uma 


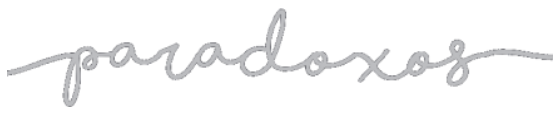

Aprendizagem ao longo da vida: a universidade da maturidade e o aprender a ser velho

CARVALHO, MILHOMEM, CARVALHO, OLIVEIRA, SILVA, 2020

perspectiva de reinserção desse grupo social de idosos, aliada a práticas de cuidado e organização da vida. Nesse cenário, a gerontologia assoma como ciência de grande repercussão e atualidade em todos os continentes (DOLL et al, 2016).

O envelhecimento hoje é acompanhado por um avanço científico que tem resultado em mudanças de paradigmas frente aos modos de envelhecer. E a gerontologia, apesar de ser um braço das ciências, tem um peculiar aspecto, pois exige a interconexão multidisciplinar e vem como uma necessidade de transcender o aspecto meramente acadêmico, promovendo a integração da fragmentação das especialidades com o mundo vivido. É aí que nos deparamos com um dos eixos da gerontologia: a gerontologia social.

A gerontologia social visa promover o envelhecimento com qualidade de vida, não apenas como um campo de pesquisa, mas como uma abordagem prática e vivencial, uma vez que proporciona aos idosos, a seus familiares e aos profissionais da área respostas que permitem melhorar o estilo de vida (MORAGAS, 1997).

No que se refere à saúde das pessoas idosas, Minayo (1994) afirma que as questões de origem biológica estão atreladas às expressões emocionais do sujeito que envelhece e se imbricam em outras questões de mesma importância, presentes no universo das relações sociais forjadas nas razões culturais e ambientais.

Ao nos depararmos com a história da UMA, vemo-nos diante de um projeto riquíssimo que valoriza os aspectos do envelhecimento humano, com uma abordagem formativa para o desenvolvimento de concepções assertivas do modo de envelhecer na contemporaneidade, que vai de encontro ao que Minayo pauta na temática sobre saúde e envelhecimento.

Nesse cenário da nova velhice, vale destacar a importância da formação acadêmica, profissional e continuada de profissionais na prática, fazendo a interlocução com as diferentes disciplinas e ambientando-se com o seu próprio objeto de estudo.

A UMA fornece um modelo único de aprendizagem significativa que vem reeducar o modo de viver e encarar a velhice, apoiado nos estudos da gerontologia social. A preparação para o envelhecimento implica a adoção de novos hábitos para viver e com-viver (OLIVEIRA; PY, 2013).

A UMA rompe barreiras ao provar que a aprendizagem na terceira idade é um processo perfeitamente viável e deve ser estimulado, respeitando as individualidades e o ritmo de cada um. Nenhuma ciência, nenhuma área do conhecimento retém o patrimônio da verdade ou é fonte de todos os valores. Todo conhecimento é processo continuo. 


\section{IMPLANTAÇÃO DA UMA EM PALMAS: UM BREVE HISTÓRICO}

De acordo com o Projeto Político Pedagógico (PPP) da UMA, de Palmas, a primeira experiência pedagógica para um envelhecimento digno e ativo aconteceu a partir de 2006. Para tanto, contou com a participação e aprovação do Colegiado de Pedagogia, da Universidade Federal do Tocantins (UFT), para a criação do programa de extensão UMA-TO, com o objetivo de conhecer "o processo de envelhecimento do ser humano para oferecer a promoção do sujeito que envelhece e provocar transformações sociais na conquista de uma velhice ativa e digna embasada no Estatuto do Idoso" (PPP-UMA, 2006, p. 5).

Outro importante fator para a consolidação do projeto UMA foi a realização da especialização latu sensu em Gerontologia ofertada pela UFT, desde 2005, cujo principal objetivo era capacitar profissionoais para atuarem na UMA (PPP-UMA, 2006, p. 5).

Desde sua implantação, a UMA de Palmas atendeu 398 estudantes idosos. No ano de 2018, contou com 58 estudantes matriculados, todos residentes em Palmas. Os estudantes atendidos pela UMA de Palmas estão na faixa etária entre 45 e 80 anos.

As aulas são ministradas por professores voluntários. A UMA atualmente possui um número oito docentes. As atividades de ensino (pesquisas, formações, oficinas, eventos) são propostas pedagógicas que buscam inserir os velhos em um processo de aprendizagem de nova fase da vida, processo esse que se relaciona com as propostas do dia a dia do século XXI.

\section{A UMA E O APRENDER A SER VELHO}

A UMA constitui-se como um espaço que proporciona a aprendizagem e a educação além do ambiente escolar. É uma proposta pedagógica de ensino para além da idade escolar convencionada por nossos contratos sociais. A proposta da instituição é articular significados de autonomia e aprendizagem para a velhice.

Como são distintas e enriquecedoras as experiências de aprendizagem pelos estudantes dentro do espaço da UMA. Buscamos captar tais experiências voltando nossa 


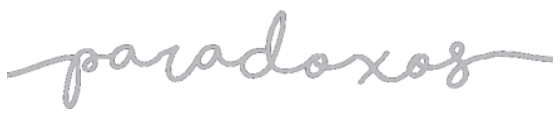

Aprendizagem ao longo da vida: a universidade da maturidade e o aprender a ser velho

CARVALHO, MILHOMEM, CARVALHO, OLIVEIRA, SILVA, 2020

escuta para as vozes dos que vivem a proposta pedagógica desenvolvida. E para atingir nosso objetivo, utilizamos a metodologia da história oral.

Entrevistamos três estudantes da UMA. Duas entrevistadas possuem o ensino fundamental, e a outra participante possui o ensino médio completo e no momento cursa Serviço Social. As entrevistadas participam da UMA há mais de dois anos.

Optamos por preservar a naturalidade das entrevistas, mantendo a oralidade e a informalidade das falas das entrevistadas que foram identificadas pelo último nome e o ano da entrevista. As narrativas indicam uma percepção da valorização do envelhecimento e a contribuição da UMA para a construção desses valores. Figueira, (2018) afirma:

\begin{abstract}
Eu aprendi a ter aquela coisa, força, ter coragem para enfrentar o envelhecimento aí fora é isso, porque até então eu não tinha coragem de ser velha; com a aprendizagem aqui da UMA eu fiquei forte, me fortaleceu ser velha, posso enfrentar qualquer coisa aí fora. Tanto que enfrentei uma faculdade.
\end{abstract}

Ou seja, nossa entrevista acredita que a UMA cumpre seu papel de abrir espaço para a aprendizagem, ao dizer que lá ela aprende a ser corajosa para ser velha. É uma relação estreita em que aprendizagem e identidade são construídas.

Para Santos (2018) os projetos da UMA são uma "ajuda com sua identidade e o mundo: Esses projetos nos ajudaram a nos identificar no meio dos outros, do mundo enfim...".

Ao serem questionadas sobre a relação de influência das vivências na UMA com o convívio social, todas as entrevistadas foram unânimes em detalhar como a aprendizagem construída na UMA tem provocado mudanças positivas em seus relacionamentos com a família e com os colegas. Tema sobre o qual Portugal (2018) enfatizou:

É claro quando eu cheguei aqui eu era muito rebelde. Eu era ignorante. Eu vinha com problemas seríssimos, eu tava saindo de depressão, transtorno bipolar tudo isso eu fiquei boa. A UMA pra mim é a minha vida, a minha família, jamais eu quero sair da UMA.

Para SANTOS (2018), a UMA tem contribuído na constituição de seu ser, potencializado a sua alegria e espontaneidade:

Sim e como! Eu participo do Parque do Idoso, a diretora de lá, toda vez que
eu chego lá ela fala que quer ser como eu, quando ela tiver mais velha, que
o exemplo dela. Ela pega o exemplo para ela, o meu jeito de ser, a minha
espontaneidade, a minha alegria, toda vez que eu chego lá ela fala isso. Eu
conheço essa UFT. Onde eu passava as pessoas vêm me cumprimentar, me
abraçar; tinha um povo, umas meninas que trabalhavam aqui, que no dia 
que eu não ia lá, parece o dia tava abafado, que eu dava alegria e luz para elas. Então isso é coisa que a gente colhe aqui é para expandir. Para você ter ideia, quanto eu entrei aqui em 2013, eu sempre sentei em um lugar específico na sala, eu passei até o ano passado sentada nesse lugar e hoje eu sento em qualquer tipo de lugar, eu converso com ela, com ela, converso com todo mundo, quando eu chego eu comprimento a sala toda. Aqui ensina você a ser onça. Igual a dra. Neila fala, quando eu cheguei aqui parecia um bichinho do mato e hoje eu falo até demais.

O que se percebe nas falas é o papel da UMA na construção de novas perspectivas das relações sociais saudáveis do velho em seu meio social. As estudantes se percebem em um contexto de desenvolvimento de potencialidade de relacionamentos, que até então era desconhecido por elas.

Durante a entrevista, perguntamos às participantes o que elas diriam se tivessem que recomendar a UMA a outro velho. O convite de Portugal (2018) foi:

O que você está fazendo na vida? Vamos para UMA, que lá você encontrará uma família amiga, vai fazer novas amizades, vai levantar o seu astral (agora eu vou arrebentar); tudo de bom que você possa imaginar você vai encontrar, amigos, professores maravilhosos, amigos, parceiros, compreensíveis.

Nessa fala percebemos o espaço de acolhimento que a UMA proporciona aos estudantes, como as relações são construídas entre estudantes e professores. Já na narrativa de Santos (2018) a UMA é um espaço de reconhecimento da identidade: "Eu diria que ele estaria entrando num lugar para a reconstituição da vida dele”. Figueira (2018) também relata sobre o ser velho: "Diria que aqui ele iria se encontrar a ser velho, não ter medo. Aqui aprender a ser velho, até então nós não sabíamos, nós estamos excluídos, aprendemos a estar com a cara aqui fora".

Nas entrevistas com as estudantes, observamos a dimensão do relacionamento e do aprendizado social, proporcionado pela proposta pedagógica da UMA, dimensão essa que se fortalece na convivência do velho com sua realidade e o seu reposicionamento diante dos enfrentamentos sociais que lhe são dispostos com o processo de envelhecimento, de modo que o aprender a envelhecer é fundamental para a autonomia e a dinâmica do ser velho. 


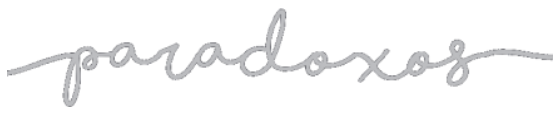

Aprendizagem ao longo da vida: a universidade da maturidade e o aprender a ser velho

CARVALHO, MILHOMEM, CARVALHO, OLIVEIRA, SILVA, 2020

\section{ALGUMAS CONSIDERAÇÕES}

A construção deste trabalho nos possibilitou a compreensão do processo de aprendizagem como algo contínuo e atemporal. A UMA cumpre com o seu papel nesse processo, fomentando um espaço para a chamada gerontologia educativa, tornando-se um espaço de referência para o envolvimento dos idosos em atividades de aprendizagem e de exploração de novos contextos e desafios. A inserção nesse espaço proporciona aos educandos idosos a realização pessoal, a participação social e a capacidade de obter respostas às suas necessidades e de situar-se historicamente na realidade em que vivem.

A UMA como instrumento de gerontologia social deve ser entendida como um processo interdisciplinar que integra diferentes facetas do envelhecimento. $\mathrm{O}$ processo de aprendizagem dos velhos ultrapassa o fenômeno homeostático; é um processo integrador, que lhes dá condições de ressignificar sua vivência, contribuir ativamente para o meio em que vivem e assumir uma nova forma de enfrentar a velhice.

\section{REFERÊNCIAS BIBLIOGRÁFICAS:}

- Livros:

ALBERTI, Verena. A filosofia e os fatos. Narração, interpretação e significado nas memórias e nas fontes orais. Tempo. RJ, 1996.

DOLL J, OLIVEIRA JF, SÁ JLM, HERÉDIA VBM. Multidimensionalidade do envelhecimento e interdisciplinaridade. In: Freitas EV e Py L (eds). Tratado de Geriatria e Gerontologia. 4 ed. Rio de Janeiro: Guanabara Koogan, 2016.

GOMES, Sandra. Políticas públicas para a pessoa idosa: marcos legais e regulatórios. São Paulo: Secretaria Estadual de Assistência e Desenvolvimento Social: Fundação Padre Anchieta, 2009.

MARCONI, M. de A.; LAKATOS, E. M. Fundamentos de metodologia científica. 5. ed. São Paulo, SP: Atlas, 2003.

MORAGAS, Ricardo Moragas. Gerontologia social: Qualidade de vida. Trad. Nara C. Rodrigues - São Paulo: Paulinas, 1997.

OLIVEIRA, JF e PY, L. Interdisciplinaridade e multiprofissionalidade em gerontologia: conjugação de saberes e ações. Educação em Rede. Rio de Janeiro: SESC, Departamento Nacional, 2013. 


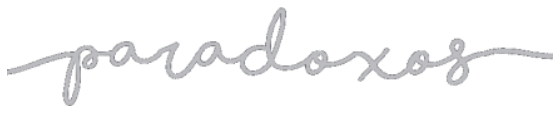

Aprendizagem ao longo da vida: a universidade da maturidade e o aprender a ser velho

PORTILHO. Evelise Maria Labatut. Aprendizagem ao Longo da Vida. Cenário Rural. SENAR, Brasília, volume 1, ano 3, 2008.

THOMPSON, Paul. A Voz do Passado: história oral. Rio de Janeiro: Paz e Terra, 2002.

- Teses e dissertações:

BILAC, D. B. N. Envelhecimento e Políticas compensatórias: O Benefício de Prestação Continuada no Município de Palmas, Tocantins. Tese (Doutorado em Sociologia). Instituto de Ciências Sociais, Universidade de Brasília - UNB. Brasília-DF. p. 297. $2014 . \quad$ Disponível em: <http://repositorio.unb.br/bitstream/10482/16702/1/2014_DorianeBragaNunesBilac.pdf $>$. Acesso em: 07 jun. 2018.

- Artigos:

MELO, A. S. C. Políticas públicas e direitos dos idosos. In: Revista Esmat, Palmas, Ano 2, n. 2, pag. 7 a $27-$ jan/dez 2010. Disponível em: <http://esmat.tjto.jus.br/publicacoes/index.php/revista_esmat/article/viewFile/147/150>. Acesso em: 07 jun. 2018.

MINAYO MCS. A interdisciplinaridade no conhecimento e na prática da saúde do idoso. In: SBGG - RJ (org.) Jornadas. Rio de Janeiro: SBGG-RJ, 1994.

- Outros:

ASSEMBLEIA GERAL DA ONU. (1948). Declaração Universal dos Direitos Humanos. (217 [III] A). Paris. Disponível em: <https://nacoesunidas.org/direitoshumanos/declaracao/>, Acesso em: 15 maio 2018.

BRASIL. Lei $\mathrm{n}^{\circ} 10.741$, de $1 .^{\circ}$ de outubro de 2003. Dispõe sobre o estatuto do idoso. Brasília-DF, 2003.

BRASIL. Constituição (1988). Constituição da República Federativa do Brasil, 1988. Brasília: Senado Federal, 1988.

BRASIL. Lei n. ${ }^{\circ} 8.078$, de 11 de setembro de 1990. Código de Defesa do Consumidor. Dispõe sobre a proteção do consumidor e dá outras providências, 1990.

BRASIL. Lei Complementar n. ${ }^{\circ}$ 75, de 20 de maio de 1993. Dispõe sobre a organização, as atribuições e o estatuto do Ministério Público da União, 1993.

BRASIL. Lei n. ${ }^{\circ}$ 8.842, de 4 de janeiro de 1994. Dispõe sobre a política nacional do idoso, cria o Conselho Nacional do Idoso e dá outras providências, 1994.

BRASIL. Lei n. ${ }^{\circ}$ 8.742, de 7 de dezembro de 1993. Dispõe sobre a organização da Assistência Social e dá outras providências, 1993. 


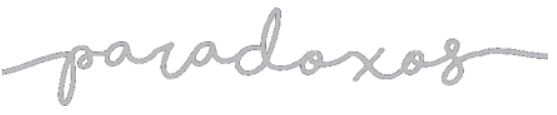

Aprendizagem ao longo da vida: a universidade da maturidade e o aprender a ser velho

BRASIL. Portaria n. ${ }^{\circ}$ 2.528, de 19 de outubro de 2006. Aprova a Política Nacional de Saúde da Pessoa Idosa, 2006.

IBGE. Pesquisa Nacional por Amostra de Domicílios - PNAD. Rio de Janeiro - RJ: IBGE, 2016. Disponível em: <https://www.ibge.gov.br/estatisticasnovoportal/sociais/habitacao/17270-pnad-continua.html?edicao=18264\&t=sobre>. Acesso em: 07 jun. 2018.

PALMAS. Universidade da Maturidade (UMA). Projeto político pedagógico. Palmas, 2006.

PALMAS. Lei $\mathrm{n}^{\circ}$ 1.888, de 2012. Dispõe de sobre a Política Municipal de Atendimento e Amparo ao Idoso, no município de Palmas - TO, 2012.

TOCANTINS. Lei n..$^{\circ} 2.001$ de 2008. Dispõe sobre a concessão da gratuidade dos transportes rodoviário e aquaviário intermunicipal à passageiros com idade acima de 60 anos, 2008.

TOCANTINS. Lei n. ${ }^{\circ} 1.335$, de 04 de setembro de 2002. Institui o Conselho Estadual do Idoso, e adota outras providências, 2002.

- Fontes Primárias:

PORTUGAL, Liliane A. R. Entrevistadora: Isabella Cristina Aquino Carvalho, Palmas TO, junho, 2018.

SANTOS, Venecy P. Entrevistadora: Isabella Cristina Aquino Carvalho, Palmas TO, junho, 2018.

FIGUEIRA, Neuzalina P. Entrevistadora: Isabella Cristina Aquino Carvalho, Palmas TO, junho, 2018. 